\title{
Prevalence of asthma symptoms in video and written questionnaires among children in four regions of Finland
}

\author{
J. Pekkanen*, S.T. Remes*, T. Husman*, M. Lindberg*, M. Kajosaari**, \\ A. Koivikko+, L. Soininen++
}

Prevalence of asthma symptoms in video and written questionnaires among children in four regions of Finland. J. Pekkanen, S.T. Remes, T. Husman, M. Lindberg, M. Kajosaari, A. Koivikko, L. Soininen. @ERS Journals Ltd 1997.

ABSTRACT: The aim of this study was to determine whether there are regional differences in the prevalence of childhood asthma in Finland. A secondary objective was to assess the concordance between a written and a video questionnaire on asthma symptoms.

In 1994-1995, the self-reported prevalence of asthma symptoms in four regions of Finland was studied among 11,607 schoolchildren aged 13-14 yrs, as part of the International Study of Asthma and Allergies in Childhood (ISAAC). The ISAAC written and video (AVQ 3,0) questionnaires were administered in the school settting.

The prevalences of any wheezing during the previous 12 months in the ISAAC video questionnaire were $10 \%$ in East Finland (Kuopio County, $\mathbf{n = 2 , 8 2 1}$ ), $\mathbf{1 2 \%}$ in

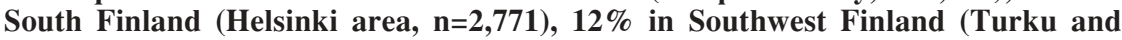
Pori County, $n=2,983$ ), and $11 \%$ in North Finland (Lapland, $n=3,032$ ). The prevalences in the ISAAC written questionnaire were $13,20,15$, and $16 \%$, respectively. The surveys were performed during winter, except in Helsinki where the survey was carried out mainly during the spring pollen season. During autumn, the prevalence in the written questionnaire in Helsinki was $16 \%$. In multivariate analysis, boys had a lower prevalence than girls, and smokers a threefold higher prevalence than nonsmokers.

In conclusion, the prevalence of childhood asthma is lower in Finland than in other European countries, and may be even lower in the eastern part of the country. In contrast to the results from some other European countries, prevalences were lower in the video than in the written questionnaire, which suggests that translating the word "wheezing" into other languages, including Finnish, may produce results that cannot be compared. The strong association of smoking with wheeze both in the video and written questionnaires should be considered in further analysis of the ISAAC study. Eur Respir J 1997; 10: 1787-1794.

It has been suggested that the incidence and prevalence of asthma among children is increasing in many countries [1-3], including Finland [4]. In Finland, the prevalence of childhood asthma has been reported to be lower than in many European countries, and in East Finland lower than in other parts of the country [5]. These variations may be due to true differences in prevalence, but may also be due to differences in the diagnostic criteria and study methods used.

Few surveys have included tests for bronchial hyperresponsiveness or clinical examinations, due to their high cost [6-8]. Thus, symptom questionnaires have been the principal instrument for measuring asthma prevalence in community surveys [9]. However, differences in wording of questionnaires and problems with translation hamper comparisons between, and sometimes also within, countries. To address these problems, a video questionnaire on clinical signs and symptoms of asthma has recently been developed and also validated [10] for use in the International Study of Asthma and Allergies in Childhood (ISAAC) [11].
*Unit of Environmental Epidemiology, National Public Health Institute, Kuopio, Finland. **Dept of Pediatrics, Helsinki University Hospital, Helsinki, Finland. +Dept of Pediatrics, Turku University Hospital, Turku, Finland. ++Provincial Government of Lapland, Finland.

Correspondence: J. Pekkanen

Unit of Environmental Epidemiology

National Public Health Institute

P.O. Box 95

FIN-70701 Kuopio

Finland

Keywords: Asthma

children

prevalence

smoking

Received: October 211996

Accepted after revision April 121997
The aim of the present study was to evaluate regional differences in the prevalence and severity of asthma among children aged 13-14 yrs in Finland, as part of the ISAAC study. As a secondary objective the concordance between the written and video questionnaire was assessed.

\section{Methods}

\section{Written and video questionnaires}

The written and video questionnaires of the ISAAC study have recently been published [11]. The written questionnaire includes questions on wheezing and cough symptoms, previous diagnosis of asthma, and questions on rhinitis and eczema. To check the translation, the Finnish questionnaires were back-translated to English. The children were also shown a video with five episodes showing children experiencing wheezing while at rest, 
at night and during exercise, waking with cough at night, and a severe attack of wheeze. After each episode, children were asked to mark down whether they themselves had experienced such symptoms. Version AVQ 3,0 of the video questionnaire, the international version, was used in the present study. In addition to the ISAAC questionnaires, children were asked about their smoking habits; the questions on smoking have been published previously [12]. The questions were: 1) Do you smoke now? no/less than once a month/about 1-2 times a month/about 1-2 times a week/daily; and 2) When is the most recent time that you smoked? yesterday or today/2 days to 1 month ago/1 month to half a year ago/half a year to one year ago/more than one year ago/never. All children completed the written questionnaire first; the order of administration of the questionnaires has been shown to have no significant effect on the responses [9]. The written and video questionnaires were easily administered in the school setting.

\section{Data collection and analysis}

In all areas, only seventh and eighth year students were included in the study, as in Finland these are the

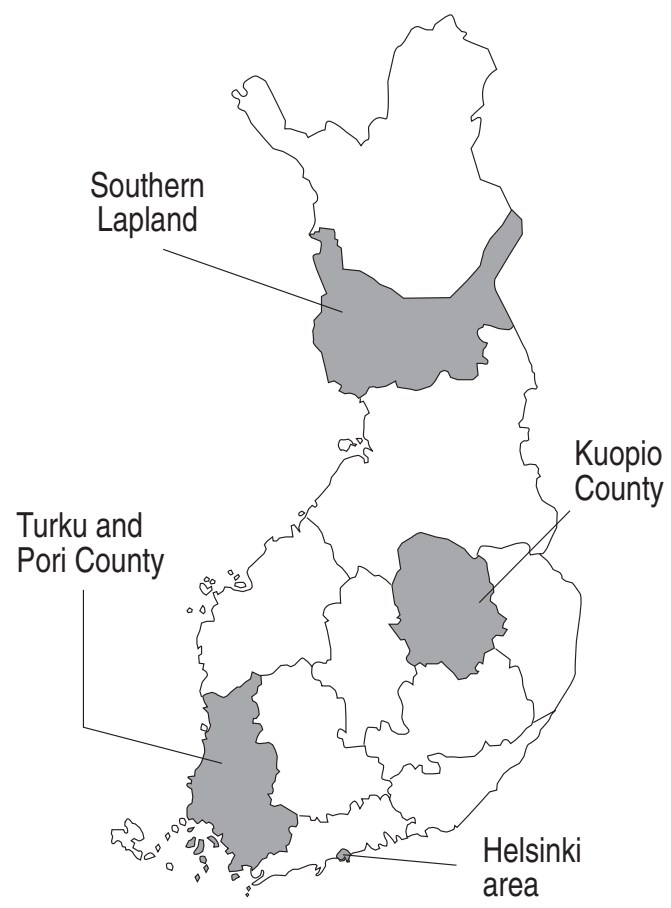

Fig. 1. - Map of the geographical areas covered by the four Finnish International Study of Asthma and Allergies (ISAAC) centres. grades including the largest number of children aged 13-14 yrs. The study was conducted in four areas of Finland: the Helsinki area; Turku and Pori County; Kuopio County; and the southern part of Lapland County (fig. 1). The schools included in the study were randomly selected [13] from all secondary schools in the areas. None of the randomly selected schools refused to participate in the study. In the Helsinki area, 17 of the 84 secondary schools in the cities of Helsinki, Espoo and Vantaa were selected; these three cities constitute the capital area of Finland. In Turku and Pori County, 13 of the 81 secondary schools were selected; Turku and Pori County is situated on the southwest coast of Finland and includes both urban and rural areas. In Kuopio County, a county in the eastern part of Finland with mostly rural areas with few small towns, 17 of the 37 secondary schools were selected. In the southern part of Lapland County, 20 of the 27 secondary schools were selected. Lapland is the most northern county of Finland, including mainly sparsely populated, rural areas and a few small towns. The northern part of Lapland County was excluded from the study, because of long distances and the small number of students in each school. The data were collected during the winter, i.e. with snow on the ground, in all centres except Helsinki, where due to practical problems the field work was started only in the early spring, interrupted for summer holidays and completed in the autumn (table 1).

All field surveys were co-ordinated by the National Public Health Institute to ensure that ISAAC methodology would be strictly adhered to. One person in each centre made almost all of the visits to schools in his/ her area. All schools were visited at least twice. Survey personnel had common written instructions in Finnish and received the same training. Sampling of the schools, and designing, printing and keying in of the questionnaires, as well as data management and analyses, were centralized.

\section{Definition of smoking and atopy}

Smoking was defined based on a combination of the two questions mentioned above, one on frequency of smoking and one on the time since the child has last smoked [12]. Children with missing or inconsistent data on either question $(n=133)$ were excluded from the analyses concerning smoking. Regular smoking was defined as smoking one or more times per week and having smoked during the last month. Occasional smoking was defined as smoking at the most one or two times per month and having smoked during the last year. No smoking was defined as no smoking currently and having

Table 1. - Study populations: response rate, gender and age

\begin{tabular}{lcccc}
\hline & Kuopio & Helsinki & Turku & Lapland \\
\hline Period of data collection & $11 / 1994-1 / 1995$ & $4-12 / 1995^{*}$ & $1-3 / 1995$ & $1-4 / 1995$ \\
Schools n & 17 & 17 & 13 & 20 \\
Responders n & $2878(97)$ & $2855(95)$ & $3085(97)$ & $3078(97)$ \\
Exclusions & $57(2)$ & $84(3)$ & $102(3)$ & $46(2)$ \\
$\quad$ Not in 13-14 yrs age range & 2821 & 2771 & 2983 & 3032 \\
Included in analysis n & $1415(50)$ & $1357(49)$ & $1479(50)$ & $1482(49)$ \\
Male n & $1383(49)$ & $1349(49)$ & $1503(50)$ & $1512(50)$ \\
Age 13 yrs n & &
\end{tabular}

*: $10 \%$ of the data were collected in autumn 1995. Values are presented as absolute number and percentage in parenthesis. 
never smoked or having stopped smoking more than a year ago.

The children reporting ever having had atopic eczema and/or hay fever in the written questionnaire were defined to have atopy.

\section{Statistical analysis}

The results are presented mainly as percentages. To assess concordance between the written and video questionnaires, overall concordance rates and the proportions of agreements were calculated [14]. Multivariate logistic regression models [15] were used to analyse the independent effects of region on the prevalence of asthma symptoms, while adjusting for the other factors. All other analyses are unadjusted.

\section{Results}

Response rates were over $95 \%$ in all four areas (table 1). Students who were outside the 13-14 yr age range were excluded from further analysis. Approximately $50 \%$ of the students were male and 13 yrs of age in all areas. Almost all the children were Finnish speaking; 99\% in Kuopio, Turku and Lapland, and 98\% in Helsinki.

Using the written questionnaire (table 2), the 1 yr prevalence of wheezing was highest in Helsinki (20\%), lowest in Kuopio (13\%), and intermediate in Turku $(15 \%)$ and Lapland (16\%). In the video questionnaire, the estimates of $1 \mathrm{yr}$ prevalence of wheezing depended on the question used (table 3). Among the three video sequences on wheezing, wheezing after exercise was the most common. If wheezing was defined as a positive response to any of the three video sequences of

Table 2. - Self-reported prevalence of asthma symptoms: findings from the written questionnaire

\begin{tabular}{|c|c|c|c|c|c|c|c|c|}
\hline & \multicolumn{2}{|c|}{$\begin{array}{l}\text { Kuopio } \\
(\mathrm{n}=2821)\end{array}$} & \multicolumn{2}{|c|}{$\begin{array}{l}\text { Helsinki } \\
(\mathrm{n}=2771)\end{array}$} & \multicolumn{2}{|c|}{$\begin{array}{c}\text { Turku } \\
(\mathrm{n}=2983)\end{array}$} & \multicolumn{2}{|c|}{$\begin{array}{l}\text { Lapland } \\
(\mathrm{n}=3032)\end{array}$} \\
\hline & $\mathrm{n}$ & $\% *$ & & $\% *$ & & $\% *$ & $\mathrm{n}$ & $\% *$ \\
\hline 1. Wheeze ever & 762 & 27 & 903 & 33 & 841 & 28 & 899 & 30 \\
\hline 2. Wheeze in past year & 366 & 13 & 542 & 20 & 448 & 15 & 487 & 16 \\
\hline 3. Attacks of wheezing in past year & & & & & & & & \\
\hline $1-3$ & 213 & 8 & 297 & 11 & 261 & 9 & 278 & 9 \\
\hline $4-12$ & 50 & 2 & 92 & 3 & 52 & 2 & 64 & 2 \\
\hline$>12$ & 26 & 1 & 47 & 2 & 33 & 1 & 37 & 1 \\
\hline 4. Sleep disturbed by wheezing in past year & & & & & & & & \\
\hline$<1$ per week & 51 & 2 & 79 & 3 & 70 & 2 & 82 & 3 \\
\hline$>1$ per week & 15 & $<1$ & 20 & 1 & 15 & 1 & 7 & $<1$ \\
\hline $\begin{array}{l}\text { 5. Severe attack of wheezing limiting } \\
\text { speech in past year }\end{array}$ & 56 & 2 & 139 & 5 & 79 & 3 & 80 & 3 \\
\hline 6. Asthma ever & 126 & 4 & 202 & 7 & 237 & 8 & 198 & 7 \\
\hline 7. Doctor-diagnosed asthma ever ${ }^{\#}$ & 115 & 4 & 168 & 6 & 209 & 7 & 176 & 6 \\
\hline
\end{tabular}

*: percentages calculated by using the number of responders included in each centre (shown in parenthesis) as the denominator; \#: the question on doctor-diagnosed asthma was stated at the end of the video questionnaire.

Table 3. - Self-reported asthma symptoms: findings from the video questionnaire

\begin{tabular}{|c|c|c|c|c|c|c|c|c|}
\hline & \multicolumn{2}{|c|}{$\begin{array}{c}\text { Kuopio } \\
(\mathrm{n}=2821)\end{array}$} & \multicolumn{2}{|c|}{$\begin{array}{l}\text { Helsinki } \\
(\mathrm{n}=2771)\end{array}$} & \multicolumn{2}{|c|}{$\begin{array}{c}\text { Turku } \\
(\mathrm{n}=2983)\end{array}$} & \multicolumn{2}{|c|}{$\begin{array}{l}\text { Lapland } \\
(\mathrm{n}=3032)\end{array}$} \\
\hline & $\mathrm{n}$ & $\% *$ & $\mathrm{n}$ & $\% *$ & $\mathrm{n}$ & $\% *$ & $\mathrm{n}$ & $\% *$ \\
\hline \multicolumn{9}{|l|}{ 1. Wheezing (while at rest) } \\
\hline Ever & 241 & 9 & 325 & 12 & 351 & 12 & 365 & 12 \\
\hline In last year & 107 & 4 & 161 & 6 & 154 & 5 & 165 & 5 \\
\hline Once or more per month & 28 & 1 & 50 & 2 & 30 & 1 & 48 & 2 \\
\hline \multicolumn{9}{|l|}{ 2. Wheezing after exercise } \\
\hline Ever & 371 & 13 & 455 & 16 & 536 & 18 & 464 & 15 \\
\hline In last year & 211 & 7 & 259 & 9 & 293 & 10 & 226 & 7 \\
\hline Once or more per month & 48 & 2 & 86 & 3 & 76 & 3 & 62 & 2 \\
\hline \multicolumn{9}{|l|}{ 3. Waking with wheezing } \\
\hline Ever & 71 & 3 & 92 & 3 & 99 & 3 & 88 & 3 \\
\hline In last year & 24 & 1 & 41 & 1 & 36 & 1 & 35 & 1 \\
\hline Once or more per month & 8 & $<1$ & 15 & 1 & 12 & $<1$ & 8 & $<1$ \\
\hline \multicolumn{9}{|l|}{ Any wheezing (any of the questions $1-3$ ) } \\
\hline Ever & 501 & 18 & 615 & 22 & 699 & 23 & 648 & 21 \\
\hline In last year & 270 & 10 & 345 & 12 & 370 & 12 & 320 & 11 \\
\hline Once or more per month & 64 & 2 & 111 & 4 & 90 & 3 & 86 & 3 \\
\hline \multicolumn{9}{|l|}{ 4. Waking with cough } \\
\hline Ever & 501 & 18 & 655 & 24 & 604 & 20 & 622 & 21 \\
\hline In last year & 308 & 11 & 407 & 15 & 373 & 13 & 349 & 12 \\
\hline Once or more per month & 57 & 2 & 104 & 4 & 76 & 3 & 57 & 2 \\
\hline \multicolumn{9}{|l|}{ 5. Severe attack of asthma } \\
\hline Ever & 139 & 5 & 151 & 5 & 155 & 5 & 189 & 6 \\
\hline In last year & 72 & 3 & 71 & 3 & 78 & 3 & 102 & 3 \\
\hline Once or more per month & 23 & 1 & 26 & 1 & 26 & 1 & 27 & 1 \\
\hline
\end{tabular}

*: percentages calculated by using the number of responders included in each centre (shown in parenthesis) as the denominator. 
wheezing, 1 yr prevalence of wheezing was slightly higher in Turku (12\%) and Helsinki (12\%) than in Kuopio $(10 \%)$ and Lapland $(11 \%)$. These estimates are lower than in the written questionnaire; the difference is highest in Helsinki and lowest in Turku. Lower prevalences for wheezing symptoms were found in Kuopio compared to all other areas; this was the case however wheezing was defined. The same tendency was seen in the question on coughing. The prevalence of cough symptoms was also highest in Helsinki.

The prevalence figures for symptoms of severe attack of asthma were low both in the written and video questionnaires (tables 2 and 3). In addition, regional differences in the $1 \mathrm{yr}$ prevalence of severe attacks were small. The prevalence of doctor-diagnosed asthma (asked in the video questionnaire) was highest in Turku (7\%), and lowest in Kuopio (4\%) (table 2).

The concordance between the written and video questionnaires was similar in all areas (table 4). In each of the four areas, $12-16 \%$ of the students reported having symptoms in one questionnaire but not the other. In most instances, students had responded positively to the written questionnaire but not to the video questionnaire. The proportion of agreement for negative responses was good in all study areas (0.82-0.87), but poor for positive responses $(0.31-0.35)$.

In Helsinki, most of the data were collected before and during the spring pollen season. In all other centres the data were collected in winter, before the pollen season. To examine the possible effect of pollen exposure on the prevalence of wheezing, the Helsinki data were divided into four time periods (fig. 2). The $1 \mathrm{yr}$ prevalence of wheezing based on the questionnaire in Helsinki ranged $17-23 \%$ during the spring and was $16 \%$ in the fall (fig. 2). These differences were not due to differences in the age and sex structure, or the prevalence of hay fever or atopic eczema in the schools surveyed during the different time periods (data not shown).

Wheezing in the preceding 12 months was slightly more common in females than in males in most instances (table 5). However, this gender difference appeared to be smaller in Turku. The $1 \mathrm{yr}$ prevalence of wheezing was also slightly higher in students aged 14 yrs than in students aged 13 yrs. There was a strong association of smoking and atopy with self-reported wheezing. Sixteen per cent of all children reported that they smoked regularly, and an additional $30 \%$ were occasional smokers. Smoking increased with age. In the Helsinki area, 24\%

Table 4. - Self-reported 1 yr prevalence of wheezing: concordance between the written and video questionnaires, proportion of agreement $(p)$ and $95 \%$ confidence interval $(95 \% \mathrm{Cl})$

\begin{tabular}{|c|c|c|c|c|c|c|c|c|c|}
\hline \multicolumn{2}{|c|}{ Questionnaire } & \multicolumn{2}{|c|}{$\begin{array}{l}\text { Kuopio } \\
(\mathrm{n}=2821)\end{array}$} & \multicolumn{2}{|c|}{$\begin{array}{l}\text { Helsinki } \\
(n=2771)\end{array}$} & \multicolumn{2}{|c|}{$\begin{array}{c}\text { Turku } \\
(\mathrm{n}=2983)\end{array}$} & \multicolumn{2}{|c|}{$\begin{array}{l}\text { Lapland } \\
(\mathrm{n}=3032)\end{array}$} \\
\hline Written & Video $^{\ddagger}$ & $\mathrm{n}$ & $\%$ & $\mathrm{n}$ & $\%$ & $\mathrm{n}$ & $\%$ & $\mathrm{n}$ & $\%$ \\
\hline Yes & Yes & 151 & 5 & 219 & 8 & 214 & 7 & 195 & 6 \\
\hline Yes & No & 215 & 8 & 323 & 12 & 234 & 8 & 292 & 10 \\
\hline No & Yes & 119 & 4 & 126 & 5 & 156 & 5 & 125 & 4 \\
\hline No & No & 2336 & 83 & 2103 & 76 & 2379 & 80 & 2420 & 80 \\
\hline \multicolumn{2}{|c|}{ Concordance rate } & 2487 & 88 & 2322 & 84 & 2593 & 87 & 2615 & 86 \\
\hline \multicolumn{2}{|c|}{ Proportion of agreement } & \multicolumn{2}{|c|}{$\mathrm{p} \quad 95 \% \mathrm{CI}$} & \multicolumn{2}{|c|}{$\mathrm{p} \quad 95 \% \mathrm{CI}$} & \multicolumn{2}{|c|}{$95 \% \mathrm{CI}$} & \multicolumn{2}{|c|}{$\mathrm{p} \quad 95 \% \mathrm{CI}$} \\
\hline \multirow{2}{*}{\multicolumn{2}{|c|}{$\begin{array}{l}\text { Negative responses } \\
\text { Positive responses }\end{array}$}} & \multirow{2}{*}{\multicolumn{2}{|c|}{$\begin{array}{l}0.86-0.88 \\
0.27-0.35\end{array}$}} & \multirow{2}{*}{\multicolumn{2}{|c|}{$\begin{array}{ll}2 & 0.81-0.83 \\
3 & 0.29-0.37\end{array}$}} & \multirow{2}{*}{\multicolumn{2}{|c|}{$\begin{array}{ll}6 & 0.85-0.87 \\
5 & 0.31-0.39\end{array}$}} & 0.85 & \multirow{2}{*}{$\begin{array}{l}0.84-0.86 \\
0.28-0.36\end{array}$} \\
\hline & & & & & & & & 0.32 & \\
\hline
\end{tabular}

$¥:$ a positive response to any of the first three video sequences; *: percentages calculated by using the number of responders included in each centre (shown in parenthesis) as the denominator.

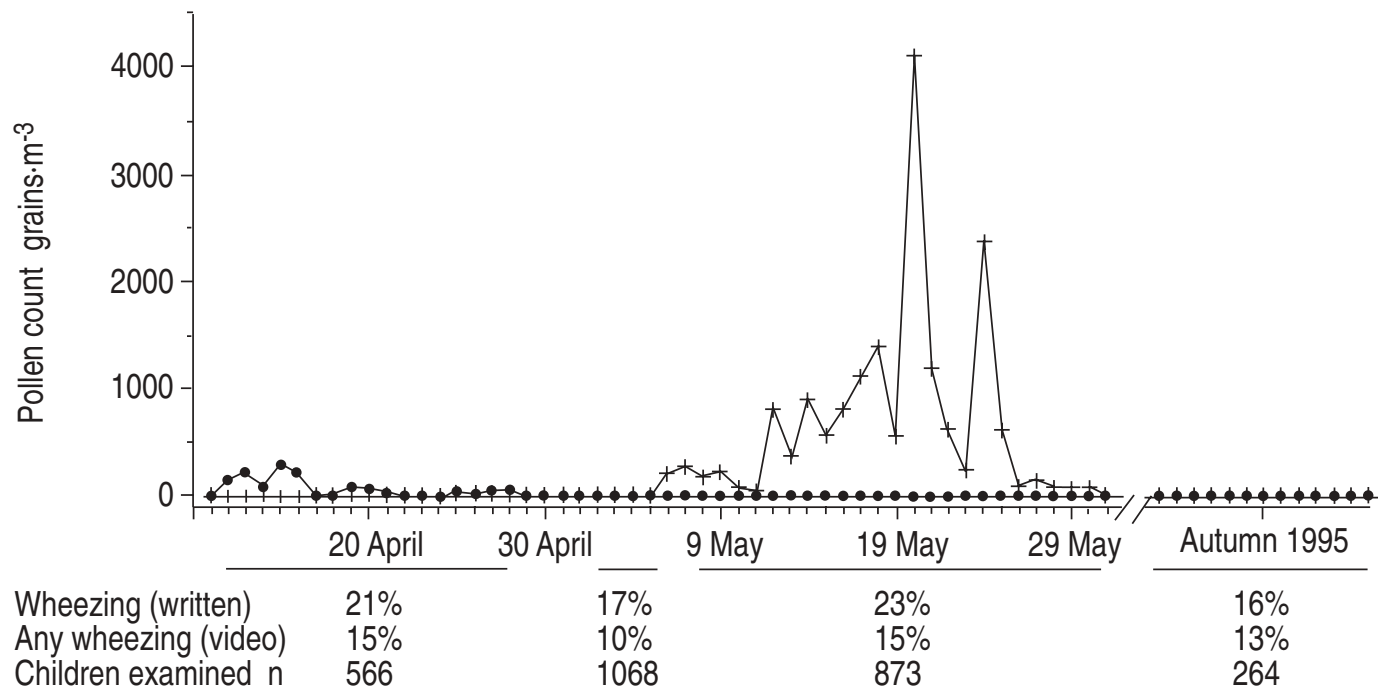

Fig. 2. - Pollen counts and prevalence of wheezing (written questionnaire) and of any wheezing (video questionnaire) in the past 12 months during the four time periods of the study in Helsinki. The four time periods are marked with horizontal bars. Only Helsinki is included in this figure, as in the other areas surveys were performed outside the pollen season. $-\_:$alder; $-+\div:$birch. 
Table 5. - Self-reported $1 \mathrm{yr}$ prevalence of wheezing by age, gender, smoking habits and atopy

\begin{tabular}{|c|c|c|c|c|c|c|c|c|c|}
\hline & \multicolumn{2}{|c|}{$\begin{array}{c}\text { Kuopio }(\mathrm{n}=2821) \\
\text { Prevalence }\end{array}$} & \multicolumn{2}{|c|}{$\begin{array}{c}\text { Helsinki }(\mathrm{n}=2771) \\
\text { Prevalence }\end{array}$} & \multicolumn{2}{|c|}{$\begin{array}{l}\text { Turku }(n=2983) \\
\text { Prevalence }\end{array}$} & \multicolumn{2}{|c|}{$\begin{array}{c}\text { Lapland }(n=3032) \\
\text { Prevalence }\end{array}$} \\
\hline & & $\mathrm{n}$ & $\%$ & $\bar{n}$ & $\%$ & $\mathrm{n}$ & $\%$ & $\mathrm{n}$ & $\%$ \\
\hline \multicolumn{10}{|c|}{ Written questionnaire } \\
\hline \multicolumn{10}{|c|}{ Wheeze in past year } \\
\hline Total & & 366 & 13 & 542 & 20 & 448 & 15 & 487 & 16 \\
\hline \multirow[t]{2}{*}{ Age } & $13 \mathrm{yrs}$ & 155 & 11 & 244 & 18 & 191 & 13 & 209 & 14 \\
\hline & 14 yrs & 211 & 15 & 298 & 21 & 257 & 18 & 278 & 18 \\
\hline \multirow[t]{2}{*}{ Gender } & Male & 153 & 11 & 235 & 17 & 223 & 15 & 210 & 14 \\
\hline & Female & 213 & 15 & 307 & 22 & 225 & 15 & 277 & 18 \\
\hline \multirow[t]{3}{*}{ Smoking } & No & 163 & 10 & 204 & 14 & 177 & 10 & 183 & 12 \\
\hline & Occasionally & 120 & 14 & 156 & 20 & 137 & 18 & 171 & 17 \\
\hline & Yes & 82 & 25 & 176 & 34 & 129 & 28 & 126 & 27 \\
\hline \multirow[t]{2}{*}{ Atopy } & No & 128 & 8 & 179 & 13 & 149 & 9 & 199 & 11 \\
\hline & Yes & 225 & 19 & 341 & 27 & 279 & 23 & 265 & 23 \\
\hline \multicolumn{10}{|c|}{ Video questionnaire } \\
\hline \multicolumn{10}{|c|}{ Wheezing while at rest ${ }^{\#}$} \\
\hline Total & & 107 & 4 & 161 & 6 & 154 & 5 & 165 & 5 \\
\hline \multirow{2}{*}{ Age } & $13 \mathrm{yrs}$ & 46 & 3 & 74 & 5 & 70 & 5 & 75 & 5 \\
\hline & $14 \mathrm{yrs}$ & 61 & 4 & 87 & 6 & 84 & 6 & 90 & 6 \\
\hline \multirow[t]{2}{*}{ Gender } & Male & 41 & 3 & 54 & 4 & 68 & 5 & 60 & 4 \\
\hline & Female & 66 & 5 & 107 & 8 & 86 & 6 & 105 & 7 \\
\hline \multirow{3}{*}{ Smoking } & No & 42 & 3 & 61 & 4 & 52 & 3 & 62 & 4 \\
\hline & Occasionally & 34 & 4 & 36 & 4 & 52 & 7 & 54 & 5 \\
\hline & Yes & 28 & 9 & 63 & 12 & 50 & 11 & 48 & 10 \\
\hline \multirow{2}{*}{ Atopy } & No & 36 & 2 & 48 & 4 & 43 & 3 & 55 & 3 \\
\hline & Yes & 70 & 6 & 111 & 9 & 105 & 9 & 101 & 9 \\
\hline \multicolumn{10}{|c|}{ Any wheezing ${ }^{+}$} \\
\hline \multirow{3}{*}{$\begin{array}{l}\text { Total } \\
\text { Age }\end{array}$} & & 270 & 10 & 345 & 12 & 370 & 12 & 320 & 11 \\
\hline & $13 \mathrm{yrs}$ & 124 & 9 & 148 & 11 & 164 & 11 & 149 & 10 \\
\hline & 14 yrs & 146 & 10 & 197 & 14 & 206 & 14 & 171 & 11 \\
\hline \multirow[t]{2}{*}{ Gender } & Male & 133 & 9 & 148 & 11 & 187 & 13 & 134 & 9 \\
\hline & Female & 137 & 10 & 197 & 14 & 183 & 12 & 186 & 12 \\
\hline \multirow{3}{*}{ Smoking } & No & 126 & 8 & 144 & 10 & 148 & 9 & 120 & 8 \\
\hline & Occasionally & 88 & 11 & 86 & 11 & 117 & 15 & 111 & 11 \\
\hline & Yes & 51 & 16 & 114 & 22 & 102 & 22 & 86 & 18 \\
\hline \multirow{2}{*}{ Atopy } & No & 110 & 7 & 112 & 8 & 130 & 8 & 127 & 7 \\
\hline & Yes & 150 & 13 & 224 & 18 & 222 & 18 & 177 & 15 \\
\hline
\end{tabular}

$\$$ : answer to the question, "have you ever had hay fever and/or atopic eczema?", in the questionnaire; \#: this video scene (depicting a young person wheezing at rest) had the highest Youden's index in relation to bronchial hyperreactivity and was, thus, selected in this table (see [10]); ${ }^{+}$: a positive response to any of the first three video sequences. The number of responders included in each centre is shown in parenthesis.

Table 6. - Association between geographical area, age, gender, smoking habit and self-reported 1 yr prevalence of asthma symptoms: findings of logistic regression analysis

\begin{tabular}{|c|c|c|c|c|c|c|c|c|c|c|}
\hline \multirow[b]{3}{*}{ Variable } & \multicolumn{4}{|c|}{ Written questionnaire } & \multicolumn{6}{|c|}{ Video questionnaire } \\
\hline & \multicolumn{2}{|c|}{ Wheezing } & \multicolumn{2}{|c|}{ Severe attack } & \multicolumn{2}{|c|}{ Wheezing at rest } & \multicolumn{2}{|c|}{ Any wheeze } & \multicolumn{2}{|c|}{ Severe attack } \\
\hline & OR & $95 \% \mathrm{CI}$ & OR & $95 \% \mathrm{CI}$ & OR & $95 \% \mathrm{CI}$ & OR & $95 \% \mathrm{CI}$ & OR & $95 \% \mathrm{CI}$ \\
\hline Kuopio\# & 1.00 & - & 1.00 & - & 1.00 & - & 1.00 & - & 1.00 & - \\
\hline Helsinki & 1.51 & $1.30-1.75$ & 2.41 & $1.76-3.31$ & 1.41 & $1.10-1.82$ & 1.25 & $1.05-1.48$ & 0.93 & $0.66-1.29$ \\
\hline Turku & 1.15 & $0.98-1.33$ & 1.29 & $0.91-1.83$ & 1.33 & $1.03-1.72$ & 1.30 & $1.10-1.53$ & 1.00 & $0.72-1.38$ \\
\hline Lapland & 1.20 & $1.04-1.40$ & 1.24 & $0.87-1.75$ & 1.36 & $1.05-1.74$ & 1.05 & $0.88-1.25$ & 1.24 & $0.91-1.69$ \\
\hline $\operatorname{Age}^{\$}$ & 1.17 & $1.05-1.30$ & 0.93 & $0.75-1.16$ & 1.00 & $0.86-1.22$ & 1.09 & $0.97-1.23$ & 1.07 & $0.85-1.34$ \\
\hline Female & 1.00 & & 1.00 & - & 1.00 & - & 1.00 & - & 1.00 & - \\
\hline Male & 0.83 & $0.75-0.92$ & 0.66 & $0.53-0.82$ & 0.64 & $0.54-0.76$ & 0.90 & $0.80-1.01$ & 0.54 & $0.42-0.68$ \\
\hline \multicolumn{11}{|l|}{ Smoking } \\
\hline No & 1.00 & - & 1.00 & - & 1.00 & - & 1.00 & - & 1.00 & - \\
\hline Occasionally & 1.51 & $1.34-1.70$ & 1.55 & $1.20-2.00$ & 1.44 & $1.17-1.76$ & 1.40 & $1.22-1.60$ & 1.38 & $1.06-1.80$ \\
\hline Yes & 2.85 & $2.50-3.25$ & 2.73 & $2.09-3.58$ & 3.12 & $2.53-3.85$ & 2.53 & $2.17-2.93$ & 2.45 & $1.85-3.25$ \\
\hline
\end{tabular}

\#: a positive response to any of the first three video sequences; \#: reference category; $\$$ : increase in age by 1 yr in the $13-14$ yrs age group. OR: odds ratio; $95 \%$ CI: $95 \%$ confidence interval. 
of students aged 14 yrs smoked regularly, but only $14 \%$ of those aged 13 yrs. The respective figures in Turku were 23 and 8\%, in Kuopio 16 and 7\%, and in Lapland 21 and $11 \%$. Regular smoking was a little more common among girls than boys in Helsinki (21 vs 17\%, respectively), in Kuopio (13 vs 10\%), and in Lapland (17 vs $15 \%$ ). Such a difference was not observed in Turku (15 vs $16 \%$, respectively). The lifetime prevalence of atopy was $46 \%$ in Helsinki, $40 \%$ in Turku, $42 \%$ in Kuopio, and $38 \%$ in Lapland. In accordance with the results in tables 2 and 3, symptom prevalences also tended to be highest in Helsinki, and lowest in Kuopio among nonsmokers and among those without atopy (table 5).

Kuopio tended to have slightly lower, and Helsinki higher prevalences of wheezing than the other areas, in the multivariate analysis, when using the written questionnaire (table 6). Kuopio also tended to have the lowest prevalences when using the video questionnaire. This finding was, however, not the case for severe attacks of asthma in the video questionnaire; this may be due to the low prevalence of severe attacks, which may make the numbers unstable. Further adjustment for atopy had little effect on differences between areas (data not shown).

Using either questionnaire, boys had a lower prevalence of self-reported asthma than girls, and smokers a higher prevalence than occasional and nonsmokers, when adjusting for the effect of other factors. In contrast, the effect of age diminished in the multivariate analysis. Thus, the higher prevalence of wheezing among the 14 yr olds was probably due to their higher prevalence of smoking.

\section{Discussion}

In the present study, regional differences in the prevalence of asthma were small. In the early 1980s, it was suggested that the prevalence of childhood asthma was lower in East Finland $(0.6 \%)$, than in South and North Finland (2.1 and 3.3\%, respectively) [5]. The prevalence included children who had both doctor-diagnosed asthma and symptoms during the previous year. The prevalence figures were also slightly lower in East Finland in the present study, both in the written and video questionnaires on asthma symptoms and in doctor-diagnosed asthma, although regional differences were statistically significant only in part of the comparisons. Differences in atopic sensitization in the study areas did not appear to explain the regional differences. However, no objective tests of atopy were performed. Thus, there still seems to be a small regional difference in the prevalence of childhood asthma in Finland. The differences may, however, have decreased since the 1980s [5].

In general, the prevalence figures both of diagnosed asthma and wheezing symptoms obtained from the present study were higher than those previously reported from Finland [5, 16-18]. Recently, a prevalence of 4.4\% of doctor-diagnosed asthma was reported among children aged 7-12 yrs in Kuopio, East Finland [6, 19], which is consistent with the present results. In Turku, a prevalence of $2.5 \%$ of doctor-diagnosed asthma was recently reported among adolescents [16]; which was less than half of that in the present study (7\%). In Southeast Finland, the lifetime prevalences of wheezing and doctor-diagnosed asthma were 11.3 and $3.7 \%$, respectively, and the prevalence of wheezing in the past year was $6.9 \%$ in the late 1970s [17]. An increase in the prevalence of doctor-diagnosed asthma has previously been reported among Finnish conscripts [4]. In a recent study, the prevalence of doctor-diagnosed asthma increased from $1.0 \%$ in 1979 to $2.8 \%$ in 1991 among representative samples of Finnish children aged 12-18 yrs [18]. These findings imply a true increase in the prevalence of asthma, although this could be due, in part, to changes in diagnostic practices or in the use of medical services [18].

The possible increase in the prevalence of childhood asthma in Finland parallels trends reported from other developed countries $[1,2]$. The reasons for this increase are unknown, but may be associated with the high living standard of the developed Western countries [20], early childhood infections [3,21], or crowding [22]. Some of these factors may also explain the regional differences in Finland. Lower living standard is one possibility, as morbidity due to other causes associated with low socioeconomic status, such as cardiovascular diseases, are also higher in East Finland [23]. Another possibility is the higher proportion of farmers in East Finland, as it has been suggested that children living on a farm may have a lower risk of asthma [24].

In the present study, the prevalence of wheezing based especially on the written questionnaire was higher in the Helsinki area than elsewhere. Although a previous study suggested that exposure to pollen did not increase the self-reported prevalence of asthma substantially [25], our results suggest that the higher prevalence in Helsinki may be due to the fact that in that region the survey was carried out during the spring pollen season, in contrast to all other areas where the data were collected in winter. During autumn, the prevalence of wheezing in Helsinki, based on the written questionnaire, was $16 \%$, which is comparable to the results from Turku and Lapland. Moreover, the difference was not seen in the video questionnaire and the prevalence of doctor-diagnosed asthma in Helsinki was equal to that in Turku and Lapland. However, the present results do not allow any firm conclusions to be drawn on prevalence of wheezing and asthma in the Helsinki area.

There is substantial variation in the prevalence of childhood asthma between different countries. Our results on wheezing symptoms (and also on doctor-diagnosed asthma) were clearly lower than in a recent international study using similar methods [9]. In that study, the $1 \mathrm{yr}$ prevalence of wheezing determined with written and video questionnaires was high $(28-40 \%)$ in Australia, New Zealand and England, and only slightly lower in Germany (20-27\%). The version of the video questionnaire used in the international study was not exactly the same as that used in the present study, but the first video scene, showing wheezing while at rest, was exactly the same in both. The influence of the video version used seems to be small; the lower prevalence in Finland was observed in all video sequences. Other studies have also reported high prevalence figures both from Australia $[1,7,26]$ and the UK [27-30]. Comparisons with these studies are, however, difficult, due to differences in the definition of asthma. 
In Finland, mortality due to asthma is very rare [31]. The prevalence of severe asthma was also low in the present study. This result is consistent with other recent studies; childhood asthma has been reported to be more severe in Australia than in the European centres [9]. Similarly, there is a marked variation between countries in mortality due to childhood asthma, which is higher in New Zealand than in the USA and many European countries [32].

In the present study, the prevalences obtained using the video questionnaire were lower than those obtained with the written questionnaire, independent of age, sex, smoking habit, or study area. This finding is in contrast to the results from the recent study using similar methods [9]. In the present study, the prevalence remained higher in the written questionnaire even when a combination of three video sequences on wheezing was used. Translating the word "wheezing" has always been problematical, as no directly comparable word exists in Finnish or in many other languages. Our finding, that the proportion of agreement for positive responses on wheezing was poor, but for negative responses was good (table 4), is consistent with our earlier result showing that the specificity of the Finnish word for "wheezing" is rather low but sensitivity is high [6]. Because the video questionnaire has been developed to overcome such translation problems [11], it may be especially useful in nonEnglish-speaking populations. Further studies including objective measurements and a clinical evaluation are needed to confirm this assumption $[6,11,33]$. In an English-speaking region [10], no difference has been found between written and video questionnaires in predicting bronchial hyperresponsiveness.

In the present study, smoking was very strongly associated with self-reported wheezing. It has previously been reported that smoking provokes asthma symptoms and is also an independent risk factor for asthma [34]. However, the association in the present study may be due, in part, to the fact that children who smoke experience more frequent nonspecific respiratory symptoms. Smoking was more common in the students aged 14 yrs than in those aged $13 \mathrm{yrs}$, indicating that many children start to smoke when they enter the Finnish secondary school at the age of 13 yrs. Similar findings have been reported previously [12]. In the present study, the higher prevalence of asthma symptoms in the students aged 14 yrs was due mainly to their higher prevalence of smoking. Girls had more wheezing symptoms and, in general, were more often smokers than boys. However, this sex difference in the prevalence of wheezing was also seen when adjusting for smoking. The higher prevalence of asthma symptoms among girls in this age group has been observed previously; the male predominance in symptom prevalence, but not in the diagnostic label of asthma, seems to diminish with age [35].

In conclusion, we found that regional differences in the prevalence and severity of childhood asthma in Finland are small, but the prevalence may be lower in East Finland. Moreover, the prevalence is lower in Finland than in other Western countries. The finding that the video questionnaire gave lower prevalences than the written questionnaire is in contrast to earlier reports [9], and underlines the problems in translating the word "wheezing" into other languages. Further studies includ- ing objective measurements and clinical evaluation to supplement symptom questionnaires should be performed to assess the validity both of written and video questionnaires. The strong association of smoking with self-reported prevalence of wheezing should be considered in further analysis and interpretation of the results from the International Study of Asthma and Allergies in Childhood.

\section{References}

1. Robertson CF, Heycock E, Bishop J, Nolan T, Olinsky A, Phelan PD. Prevalence of asthma in Melbourne schoolchildren: changes over 26 yrs. BMJ 1991; 302: 1116-1118.

2. Burney PGJ, Chinn S, Rona RJ. Has the prevalence of asthma increased in children? Evidence from the national study of health and growth 1973-1986. BMJ 1990; 300: 1306-1310.

3. Cookson W, Moffatt M. Asthma: an epidemic in the absence of infection? Science 1997; 275: 41-42.

4. Haahtela T, Lindholm H, Björksten F, Koskenvuo K, Laitinen LA. Prevalence of asthma in Finnish young men. BMJ 1990; 301: 266-268.

5. Pöysä L, Korppi M, Pietikäinen M, Remes K, JuntunenBackman K. Asthma, allergic rhinitis and atopic eczema in Finnish children and adolescents. Allergy 1991; 46: 161-165.

6. Remes ST, Korppi M, Remes K, Pekkanen J. Prevalence of asthma at school age: a clinical population-based study in Eastern Finland. Acta Paediatr 1996; 85: 5963.

7. Peat JK, van den Berg RH, Green WF, Mellis CM, Leeder SR, Woolcock AJ. Changing prevalence of asthma in Australian children. BMJ 1994; 308: 1591-1596.

8. Norrman E, Rosenhall L, Nyström L, Bergström E, Stjernberg N. High prevalence of asthma and related symptoms in teenagers in Northern Sweden. Eur Respir J 1993; 6: 834-839.

9. Pearce N, Weiland S, Keil U, et al. Self-reported prevalence of asthma symptoms in children in Australia, England, Germany and New Zealand: an international comparison using the ISAAC protocol. Eur Respir $J$ 1993; 6: 1455-1461.

10. Shaw R, Woodman K, Ayson M, et al. Measuring the prevalence of bronchial hyperresponsiveness in children. Int J Epidemiol 1995; 24: 597-602.

11. Asher MI, Keil U, Anderson HR, et al. International study of asthma and allergies in childhood (ISAAC): rationale and methods. Eur Respir J 1995; 8: 483-491.

12. Pallonen U, Vartiainen E, Pöyhiä P, Luukkainen A-L, Koskela K, Puska P. The North Karelia Youth Project: description and feasibility of the intervention. Publications of the National Public Health Institute series B2/ 1982, Government Printing Centre, Helsinki, 1982.

13. Armitage P, Berry G. In: Statistical Methods in Medical Research. Oxford, Blackwell Scientific Publications, 1987; p. 518.

14. Grant JM. The fetal heart trace is normal, isn't it? Observer agreement of categorical assessments. Lancet 1991; 337: 215-218.

15. SAS Institute Inc. SAS/STAT ${ }^{\circledR}$ User's Guide. Version 6. 4th Edn, Volume 1-2. SAS Institute Inc., Cary NC.

16. Varjonen E, Kalimo K, Lammintausta K, Terho P. Prevalence of atopic disorders among adolescents in Turku, Finland. Allergy 1992; 47: 243-248. 
17. Haahtela T. Allergy in young people: an epidemiological study of immediate skin test reactivity and allergic disorders among adolescents and conscripts in southeast Finland. Helsinki University, Medical Dissertation, 1980.

18. Rimpelä A, Savonius B, Rimpelä M, Haahtela T. Asthma and allergic rhinitis among Finnish adolescents in 1977-1991. Scand J Soc Med 1995; 1: 60-65.

19. Timonen KL, Pekkanen J, Korppi M, Vahteristo M, Salonen RO. Prevalence and characteristics of children with chronic respiratory symptoms in Eastern Finland. Eur Respir J 1995; 8: 1155-1160.

20. von Mutius E, Fritzsch C, Weiland SK, Röll G, Magnussen $\mathrm{H}$. Prevalence of asthma and allergic disorders among children in united Germany: a descriptive comparison. BMJ 1992; 305: 1395-1399.

21. Frick OL, German DF, Mills J. Development of allergy in children: association with virus infection. $J$ Allergy Clin Immunol 1979; 63: 228-241.

22. von Mutius E, Martinez FD, Fritzsch C, Nicolai T, Roell G, Thiemann HH. Skin test reactivity and number of siblings. BMJ 1994; 308: 692-695.

23. Koskinen S. Origins of regional differences in mortality from ischaemic heart disease in Finland. National Research and Development Centre for Welfare and Health, Helsinki, Finland. Research reports, 1994; 41.

24. Husman T, Susitaival P, Kalliokoski P. Atopic diseases in farmer families and in nonfarming population in Finland. Allergy 1996; 32 (Suppl. 51): p. 22.

25. Stewart AW, Asher MI, Clayton T, et al. The effect of season on responses to ISAAC questions about asthma, rhinitis and eczema in children. Eur Respir J 1995; (Suppl. 19): 53s.
26. Robertson CF, Bishop J, Sennhauser FH, Mallol J. International comparison of asthma prevalence in children: Australia, Switzerland, Chile. Pediatr Pulmonol 1993; 16: 219-226.

27. Ninan TK, Russel G. Respiratory symptoms and atopy in Aberdeen schoolchildren: evidence from two surveys 25 years apart. BMJ 1992; 304: 873-875.

28. Austin JB, Russel G, Adam MG, Mackintosh D, Kelsey S, Peck DF. Prevalence of asthma and wheeze in the Highlands of Scotland. Arch Dis Child 1994; 71: 211216.

29. Burr ML, Butland BK, King S, Vaughan-Williams E. Changes in asthma prevalence: two surveys 15 years apart. Arch Dis Child 1989; 64: 1452-1456.

30. Stratchan DP, Anderson HR, Limb ES, O'Neill A, Wells N. A national survey of asthma prevalence, severity, and treatment in Great Britain. Arch Dis Child 1994; 70: $174-178$.

31. Kinnula V, Nurmela T, Liippo K, Tala E, Huhti E. Fatal asthma in two regions of Finland. Ann Clin Res 1988; 20: 189-194.

32. Foucard T, Graff-Lonnevig V. Asthma mortality rate in Swedish children and young adults 1973-1988. Allergy 1994; 49: 616-619.

33. Burr ML. Diagnosing asthma by questionnaire in epidemiological surveys. Clin Exp Allergy 1992; 22: 509-510.

34. Larsson L. Incidence of asthma in Swedish teenagers: relation to sex and smoking habits. Thorax 1994; 50: 260-264.

35. Sennhauser FH, Kuhni CE. Prevalence of respiratory symptoms in Swiss children: is bronchial asthma really more prevalent in boys? Pediatr Pulmonol 1995; 19: 161-166. 